\title{
The effects of smoking (nicotine nystagmus) on Dynamic Visual Acuity
}

\author{
GERALD M. LONG and MARTIN E. FRANKLIN \\ Villanova University, Villanova, Pennsylvania
}

\begin{abstract}
The effects of smoking on the resolution of moving targets were assessed under a range of velocity and duration conditions for both heavy and light smokers. In no instance was the smoking found to impair dynamic acuity. It was concluded that the nicotine nystagmus reported by previous investigators has little practical impact on a dynamic acuity task and, by implication, on real-world tasks involving the resolution of moving targets.
\end{abstract}

Within the last decade, dynamic visual acuity (DVA), an individual's ability to resolve a moving target, has been of increasing interest to researchers. Although research in this ability can be traced back to the work of Ludvigh and Miller in the late 1940s and 1950s (e.g., Ludvigh, 1949; Miller, 1958; Miller \& Ludvigh, 1962), DVA research over the last 30 years has been rather sporadic. Nevertheless, this work has clearly determined that DVA is relatively independent of traditional static acuity measures (see Morrison, 1980) and may be related to many real-world activities in which the resolution of moving targets plays a crucial role. These activities include driving (Henderson \& Burg, 1973), flying (DeKlerk, Eernst, \& Hoogerheide, 1964; Goodson \& Miller, 1959), and various sports (Beals, Mayyasi, Templeton, \& Johnston, 1971; Falkowitz \& Mendel, 1977; Morris \& Kreighbaum, 1977; Sanderson \& Whiting, 1974; Trachtman, 1973). Consequently, the Committee on Vision of the National Research Council recently (1985) described DVA as one of four vision measures that may predict real-world activities more reliably than do traditional vision measures. Almost certainly, research interest in this ability and the role it plays in various activities will continue to increase in the foreseeable future.

A significant portion of previous DVA research has sought to uncover the neural and motor mechanisms that underlie DVA, such as the saccadic and pursuit eye movement systems (e.g., Brown, 1972a, 1972b, 1972c; Long \& Garvey, 1988). As mentioned above, another popular research approach with DVA has been to determine the predictive value of DVA for various activities. A third, closely related, approach has been to investigate the impact of particular variables on DVA. These include not only stimulus variables such as target conspicuity (Goodson \& Morrison, 1981a, 1981b) and target color (Long \& Garvey, 1988), but also organismic variables such as gender (e.g., Burg \& Hulbert, 1961) and aging (Burg \& Hulbert, 1961; Crambert, 1988). In a similar vein, the

Reprint requests should be sent to Gerald M. Long, Department of Psychology, Villanova University, Villanova, PA 19085. impact of various drugs and alcohol on DVA has also been investigated (Brown, Adams, Haegerstrom-Portnoy, Jones, \& Flom, 1975; Garvey, Goebel, Tyrrell, \& Gish, 1988). This latter work has sought both to identify the critical processes underlying DVA (and their sensitivity to such substances) and to suggest the consequences of the ingestion of such substances on real-worl activities involving dynamic target resolution. The present research, which focused on the consequences of tobacco smoking on DVA, falls within this final category of DVA research.

Sibony, Evinger, and Manning (1987a) recently reported that cigarette smoking produces a brief alteration in normal eye movement activity. Of particular relevance for the present work is the finding that, for a 10- to 15-min period following tobacco smoking, a vertical nystagmus is superimposed on horizontal pursuit movements. In other words, while tracking a horizontally moving target, the eyes exhibit rapid vertical "jerks" that are normally absent in such a pursuit task. These abnormal eye movements have been attributed to the uptake of nicotine through the lungs, with a special role played by central vestibular pathways (Sibony, Evinger, \& Manning, 1987b).

In the present study, we sought to determine the consequences, if any, of nicotine nystagmus on DVA. The work by Sibony et al. (1987a, 1987b) involved the direct monitoring of eye movements following smoking; however, it was unclear whether the reported nystagmus would impede resolution of moving targets. Although such a possibility appears reasonably likely, it also was very possible that the nystagmus would have little practical effect because of the durations involved. Hence, in the present study, we sought to determine the impact of smoking on DVA performance under a range of target velocity and target duration conditions. The practical importance of such determinations, in terms of real-world activities undertaken by smokers, is clearly apparent.

\section{METHOD}

\section{Subjects}

Four student volunteers were used, 2 heavy smokers and 2 light smokers. Following the criteria adopted by Sibony et al. (1987a, 1987b), 
a heavy smoker was defined as an individual who smoked one pack or more of cigarettes per day, and a light smoker was defined as an individual who smoked one or two cigarettes per day. Prior to each observer's participation, his/her static acuity was determined to be $20 / 20$ with a Titmus Vision Tester. Each individual participated in 12 40-min sessions that followed a single 40 -min practice session. All sessions for a single subject were conducted within a 3-week period. Each observer was reimbursed for his/her participation at a rate of $\$ 4.50 / \mathrm{h}$.

\section{Apparatus and Stimuli}

The apparatus and stimuli, which were modified versions of those used in numerous previous studies over the past 30 years (e.g., Brown, 1972b; Brown et al., 1975; Goodson \& Morrison, 1980; Ludvigh \& Miller, 1958), have been described elsewhere (Long \& Garvey, 1988; Long \& Penn, 1987). Landolt-C targets were projected from a Kodak Ektagraphic projector (Model IIIAM) onto a front-surface mirror. The mirror, which was mounted vertically on a variable-speed turntable, reflected the target toward a $180^{\circ}$ white hemicylindrical screen positioned $1.5 \mathrm{~m}$ from the observer. Following the recommendation by Brown (1972a), the gap in the Landolt $C$ was located in one of the four diagonal positions: upper right, lower right, upper left, or lower left. The size of the critical detail (gap) in the Landolt $\mathrm{C}$ ranged across trials from $2.3^{\prime}, 3.4^{\prime}, 4.6^{\prime}, 5.7^{\prime}, 6.8^{\prime}, 11.4^{\prime}, 13.7^{\prime}, 17.4^{\prime}, 19.0^{\prime}, 26.7^{\prime}, 31.8^{\prime}$, and $43.2^{\prime}$. The projected Landolt- $\mathrm{C}$ targets were positive-contrast targets: they appeared as luminous targets against the white background rather than as dark targets on a bright background (see Brown et al., 1975). A variable-speed motor controlled the rate of rotation of the turntable (and, consequently, the velocity of the projected target across the cylindrical screen). A Beckman voltmeter permitted precise monitoring of motor voltage, and thereby allowed rapid and reliable adjustment of target velocities from one trial run to the next. High-intensity projector bulbs (General Electric code EXR), with manufacturer's-rated color temperature of $3,350^{\circ} \mathrm{K}$, were used in the projector. These bulbs correspond most closely to CIE Standard Illuminant B.
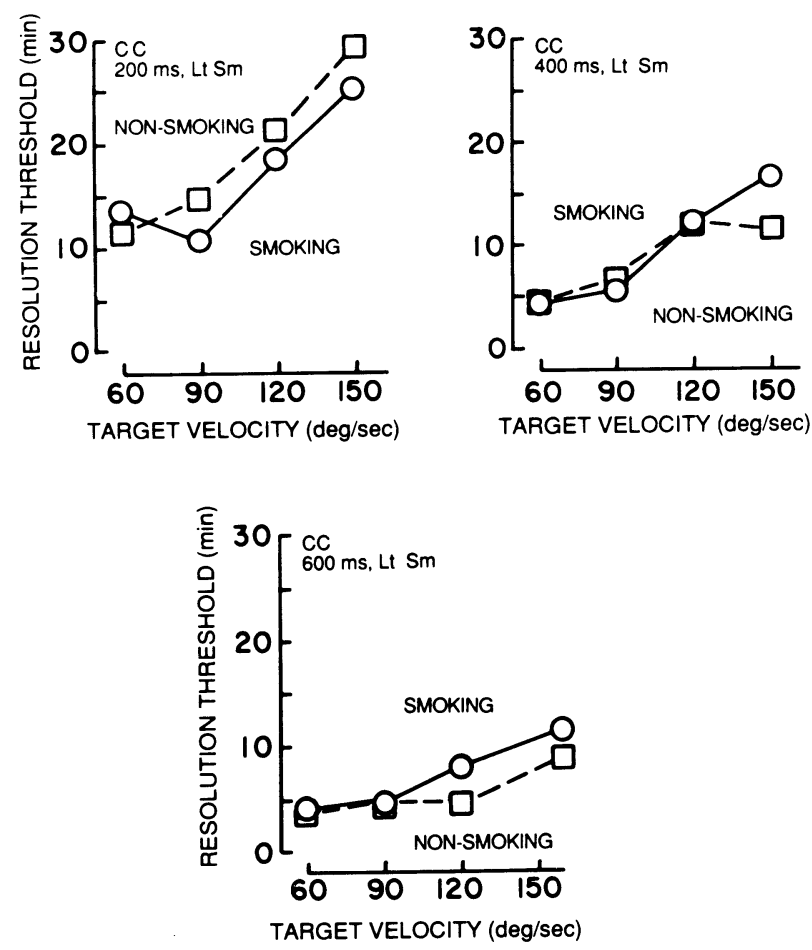

Figure 1. Minimum target resolved as a function of target velocity under the smoking and nonsmoking conditions for 200- (upper left panel), 400- (upper right panel), and 600-msec (lower panel) targets for Observer C.C., a light smoker.
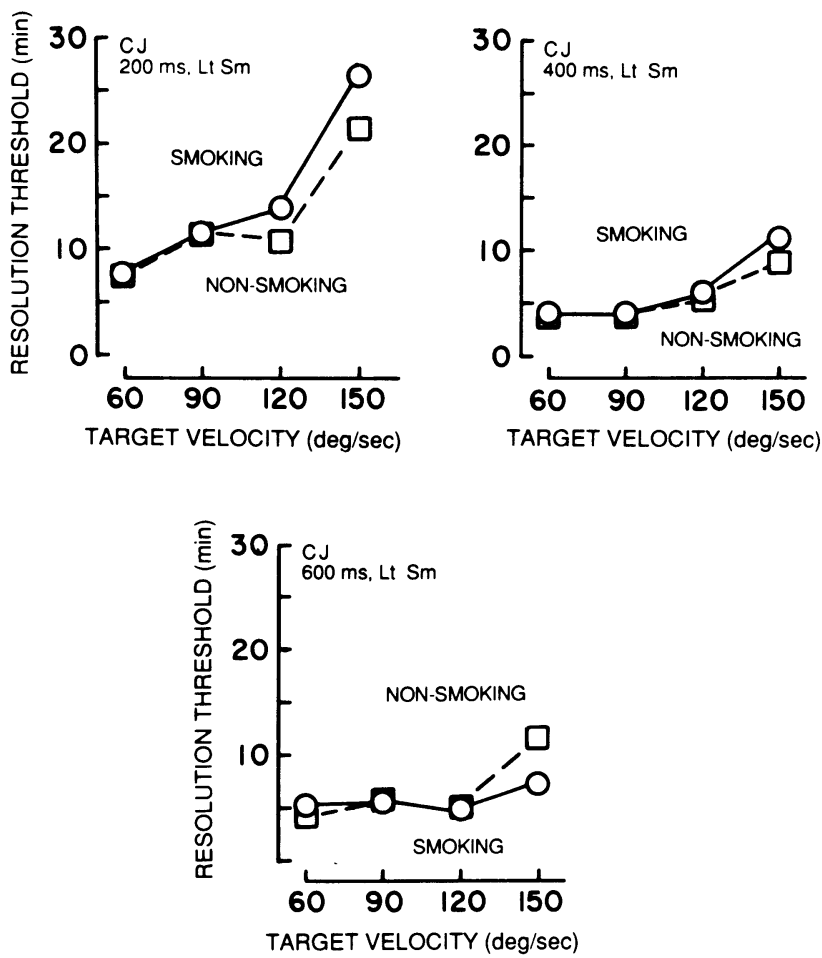

Figure 2. Minimum target resolved as a function of target velocity under the smoking and nonsmoking conditions for 200- (upper left panel), 400- (upper right panel), and 600-msec (lower panel) targets for Observer C.J., a light smoker.

There were four targets at each size of Landolt C, with each target having a different gap location (upper right, lower right, upper left, or lower left). Background luminance was held constant at a low photopic level of $31 \mathrm{~cd} / \mathrm{m}^{2}$. The luminance of the targets, which was controlled by positioning Kodak Wratten No. 96 neutral-density filters in front of the projector, was constant at $35 \mathrm{~cd} / \mathrm{m}^{2}$. These target and background levels were chosen on the basis of pilot work, which indicated that observers found them phenomenally "comfortable," while they clearly were suprathreshold and did not produce any ceiling effects in performance.

The observer was seated directly below the turntable with his/her head carefully positioned in a head- and chinrest. A supporting elastic head strap held the observer's head tightly against the headrest to minimize any head movements. A Gerbrands millisecond shutter/driver system (Series 300-C) controlled target duration $(200,400$, or $600 \mathrm{msec})$. The briefest duration permits only a single saccadic eye movement (Brown, 1972a; Collewijn \& Tamminga, 1984), and thereby allows an estimation of the precision of the mechanisms underlying that type of eye movement. The 400-msec duration is rather typical of DVA work (e.g., Miller \& Ludvigh, 1962; Morrison, 1980) and, for slower target speeds, permits both saccadic and pursuit eye movements. The 600 -msec duration allows multiple saccades as well as more extensive pursuit movements (e.g., Collewijn \& Tamminga, 1984; Robinson, 1965). The shutter was mounted on the projector lens, and target onset was controlled by a stationary mercury switch mounted on the turntable's base, which was initiated by the passing of a small projecting metal bar on the turntable past the switch.

\section{Procedure}

The procedure was modified slightly from that employed by other investigators (e.g., Goodson \& Morrison, 1980) and has been used quite satisfactorily in previous published work from our laboratory (Long \& Garvey, 1988; Long \& Penn, 1987). For a given set of stimulus conditions (duration, velocity, and smoking), a Landolt-C target was presented 
on a trial following a verbal ready signal from the experimenter. A trial run always began with a large, easily resolved target size. When the observer correctly reported the position of the gap (which varied randomly over the four positions from trial to trial), target size was reduced for the next trial. This was continued over successive trials until an incorrect response was made. At that point, the Landolt $\mathrm{C}$ was increased in size to that of the previous trial, and the trial was repeated. If correctly resolved, target size was again reduced. When the observer erred for a second time with a given target size, the trial run was stopped, and the next larger size was recorded as the threshold size resolvable for that set of stimulus conditions. A new set of conditions was then introduced, and the procedure was repeated.

The first 40-min session was a practice session that served to familiarize the subject with the experimental setting and the DVA task requirements. Previous work had suggested the advisability of employing a practice session before undertaking actual DVA measurements. Twelve 40 -min experimental sessions then followed over a 2-week period. In each session, the observer received both a smoking and a nonsmoking condition, the order of which was randomized for each session. For a given session, the target duration was randomly assigned to one of the three levels used $(200,400$, or $600 \mathrm{msec})$, and the observer's resolution thresholds for the four target velocities (in randomized sequence) were determined. A 5-min period separated the smoking and nonsmoking halves of each session.

In the smoking condition within each session, the observer was required to smoke a single cigarette by puffing at a rate of about one puff every 10-15 sec for approximately $1.5 \mathrm{~min}$. This procedure was borrowed from Sibony et al. (1987b). Immediately after finishing the cigarette, the observer's DVA was then quickly determined as described above for the four target velocities at the single target duration selected for that session. The determination of these four scores required about $15 \mathrm{~min}$, which is within the time period for the duration of nicotine nystagmus reported by Sibony et al. (1987b). Except for the cigarette smoking, the nonsmoking half of each session was identical to the smoking half. By having 12 sessions per observer, the resolution threshold for
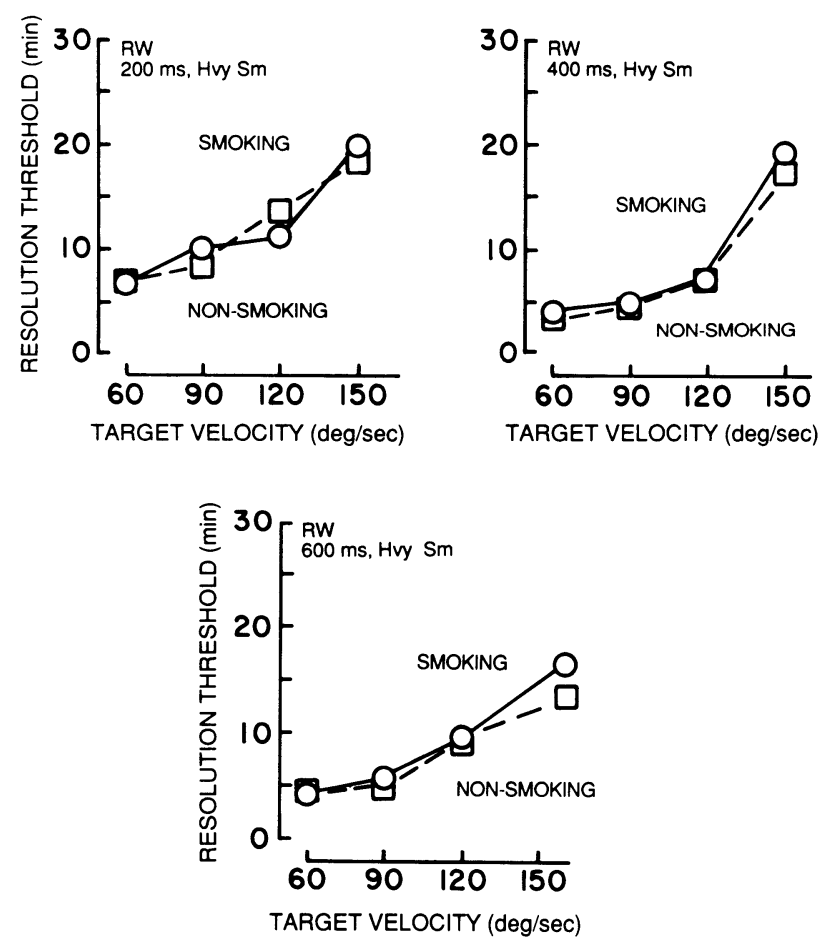

Figure 3. Minimum target resolved as a function of target velocity under the smoking and nonsmoking conditions for 200- (upper left panel), 400- (upper right panel), and 600-msec (lower panel) targets for Observer R.W., a heavy smoker.
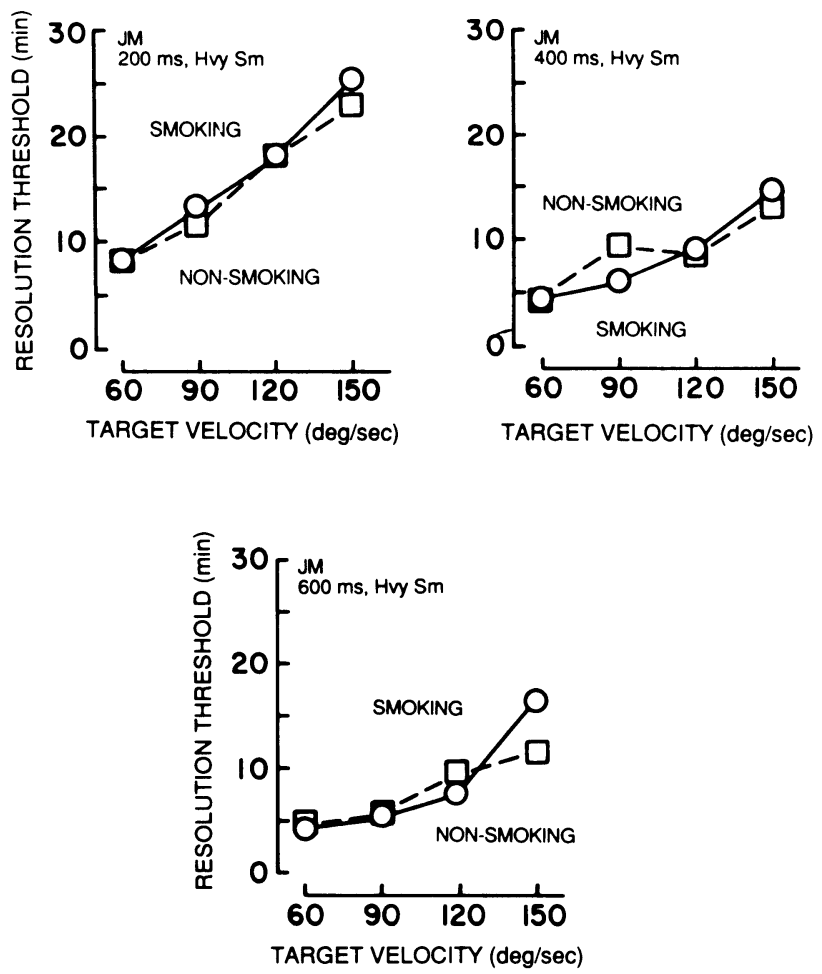

Figure 4. Minimum target resolved as a function of target velocity under the smoking and nonsmoking conditions for 200- (upper left panel), 400- (upper right panel), and 600-msec (lower panel) targets for Observer J.M., a heavy smoker.

each duration $\times$ velocity combination was assessed four times under both the smoking and the nonsmoking conditions for each observer.

\section{RESULTS}

The results for each of the 4 observers are shown in Figures 1-4. Figures 1 and 2 present mean resolution thresholds under the smoking and nonsmoking conditions as a function of target velocity for the 2 light smokers. Figures 3 and 4 present the analogous data for the 2 heavy smokers. The three sets of axes in each figure represent the three target durations of 200,400 , and $600 \mathrm{msec}$.

The effects of target velocity and target duration on DVA that are shown in Figures 1-4 are precisely as expected. The resolution thresholds decrease (i.e., DVA improves) as either target velocity decreases or target duration increases (especially between 200 and $400 \mathrm{msec}$ ). These findings are consistent with numerous published data (e.g., see reviews by Miller \& Ludvigh, 1962; Morrison, 1980), and they strongly suggest that our apparatus and procedures indeed assess DVA as typically reported in the literature. Furthermore, the large individual differences in DVA among the observers who exhibit identical static acuity are also consistent with previous work (e.g., Burg, 1966; Long \& Penn, 1987).

Concerning the specific effect of smoking on DVA, no consistent pattern is evident for either the light or heavy 
smokers. Although it may appear in some of the figures that the two curves may be different, there is no reliable pattern across observers, and, most importantly, under no set of conditions do the points for the smoking and nonsmoking conditions differ by more than even one standard deviation. In the vast majority of cases, the curves are essentially identical. Hence, no effect of smoking on DVA under the conditions examined can be demonstrated.

\section{DISCUSSION}

The results from this study are rather straightforward. Under a range of stimulus conditions that encompassed those traditionally employed in DVA work, no effect of smoking was discernible on resolution performance. From these results, we favor the conclusion that nicotine nystagmus exhibits a minimal effect on DVA and, relatedly, has no direct consequences on resolution capability in applied settings in which the resolution of moving targets is involved. However, we realize that this null effect must be treated with caution. On the one hand, the precision available to us with our apparatus and procedures may have been insufficient to assess a very subtle effect of smoking on performance. Although this is quite possible, the existence of a very weak effect speaks directly to the issue of the practical significance of nicotine nystagmus. On the other hand, a selection of different stimulus conditions (e.g., lower or higher background levels, lower or higher target velocities, etc.) have been more amenable to the detection of a smoking effect. However, what these conditions might be is unknown to us, and the conditions in the present work were chosen so as to be representative of those favored in the bulk of previous DVA research. In summary then, we offer the tentative conclusion that, for the particular conditions examined and within the precision of measurement available to us, smoking was found to exhibit no apparent effect on DVA.

\section{REFERENCES}

Beals, R. P., Mayyasi, A. M., Templeton, A. E., \& Johnston, W. L. (1971). The relationship between basketball shooting performance and certain visual attributes. American Journal of Optometry \& Archives of American Academy of Optometry, 48, 585-590.

Brown, B. (1972a). Resolution thresholds for moving targets at the fovea and in the peripheral retina. Vision Research, 12, 293-304.

Brown, B. (1972b). Dynamic visual acuity, eye movements and peripheral acuity for moving targets. Vision Research, 12, 305-321.

BRown, B. (1972c). The effect of target contrast variation on dynamic visual acuity and eye movements. Vision Research, 12, 1213-1224. Brown, B., Adams, A. J., Haegerstrom-Portnoy, G., Jones, R. T., \& FLom, M. C. (1975). Effects of alcohol and marijuana on dynamic visual acuity: I. Threshold measurements. Perception \& Psychophysics, 18, 441-446.

BURG, A. (1966). Visual acuity as measured by dynamic and static tests: A comparative evaluation. Journal of Applied Psychology, 50, 460-466.

BURG, A., \& HulberT, S. (1961). Dynamic visual acuity as related to age, sex, and static acuity. Journal of Applied Psychology, 45, 111-116.

Collewijn, H., \& TAMminga, E. P. (1984). Human smooth pursuit and saccadic eye movements during voluntary pursuit of different target motions on different backgrounds. Journal of Physiology, 351, 217-250.

COMmitTEE ON Vision. (1985). Emergent techniques for the assessment of visual performance. Washington, DC: National Academy Press.

Crambert, R. (1988). The effects of aging on Dynamic Visual Acuity. Unpublished master's thesis, Villanova University, Villanova, PA.
DeKlerk, L. F., Eernst, J., \& Hoogerheide, J. (1964). The dynamic visual acuity of 30 selected pilots. Aeromedica Acta, 9, 129-136.

FALKowitz, C., \& MENDEL, H. (1977). The role of visual skills in batting averages. Optometric Weekly, 68, 33-36.

Garvey, P. M., Goebel, C. C., Tyrrell, R. A., \& Gish, K. W. (1988). Effects of alcohol consumption on contrast sensitivity for static and dynamic targets. Investigative Ophthalmology \& Visual Science, 29, 134.

Goodson, J. E., \& Miller, J. W. (1959). Dynamic visual acuity in an applied setting. Aerospace Medicine, 30, 755-763.

GoOdsON, J. E., \& MoRrIsON, T. R. (1980). Stimulus determinants of dynamic visual acuity: I. Background and exploratory data (Tech. Rep. No. 1270). Pensacola, FL: Naval Aerospace Medical Research Laboratory.

Goodson, J. E., \& Morrison, T. R. (1981a). Stimulus determinants of Dynamic Visual Acuity: II. Effects of limiting target surround (Tech. Rep. No. NAMRL 1274). Pensacola, FL: Naval Aerospace Medical Research Laboratory.

GoODSON, J. E., \& MORRISON, T. R. (1981b). Stimulus determinants of Dynamic Visual Acuity: III. Effects of proximal borders and limited surround (Tech. Rep. No. NAMRL 1276). Pensacola, FL: Naval Aerospace Medical Research Laboratory.

HENDERSON, R. L., \& BURG, A. (1973). The role of vision and audition in truck and bus drivers [Report No. RM-(1)-5260/000/00]. Santa Monica, CA: Systems Development Corp.

LONG, G. M., \& GARVEY, P. M. (1988). The effects of target wavelength on Dynamic Visual Acuity under photopic and scotopic viewing. $\mathrm{Hu}$ man Factors, 30, 3-13.

Long, G. M., \& PenN, D. L. (1987). Dynamic visual acuity: Normative functions and practical implications. Bulletin of the Psychonomic Society, 25, 253-256.

LUDVIGH, E. J. (1949). Visual acuity while one is viewing a moving object. Archives of Ophthalmology, 42, 14-22.

LUDVIGH, E., \& MILLER, J. W. (1958). Study of visual acuity during the ocular pursuit of moving test objects: I. Introduction. Journal of the Optical Society of America, 48, 799-802.

MILLER, J. W. (1958). Study of visual acuity during the ocular pursuit of moving test objects: II. Effects of direction of movement, relative movement, and illumination. Journal of the Optical Society of America, 48, 803-808.

MiLleR, J. W., \& LUDVIGH, E. J. (1962). The effect of relative motion on visual acuity. Survey of Ophthalmology, 7, 83-116.

MorRis, G. S., \& KREIGHBAUM, E. (1977). Dynamic visual acuity of varsity women volleyball and basketball players. Research Quarterly of the American Association of Health \& Physical Education, 48, 480-483.

MORRISON, T. R. (1980). A review of dynamic visual acuity (NAMRL Monograph 28). Pensacola, FL: Naval Aerospace Medical Research Laboratory.

Robinson, D. A. (1965). The mechanics of human smooth pursuit eye movements. Journal of Physiology, 180, 569-591.

SANDERSON, F. H., \& Whiting, H. T. A. (1974). Dynamic visual acuity and performance in a catching task. Journal of Motor Behavior, 6, 87-94.

Sibony, P. A., Evinger, C., \& MANning, K. A. (1987a). Effects of tobacco on pursuit eye movements and blinks. Investigative Ophthalmology \& Visual Science, 28, 316.

Sibony, P. A., Evinger, C., \& MANNing, K. A. (1987b). Tobaccoinduced primary-position upbeat nystagmus. Annals of Neurology, 21, 53-58.

Trachtman, J. N. (1973). The relationship between ocular motilities and batting average in Little Leaguers. American Journal of Optometry \& Archives of American Academy of Optometry, 50, 914-919.

(Manuscript received July 5, 1988.) 